Research Article

\title{
Finite-Time Speed Control of Marine Diesel Engine Based on ADRC
}

\author{
Yuanqing Wang $\mathbb{D}^{1,2}$ Guichen Zhang $\mathbb{D}^{1},{ }^{1}$ Zhubing Shi, ${ }^{2}$ Qi Wang, Juan Su, ${ }^{2}$ \\ and Hongyu Qiao ${ }^{2}$ \\ ${ }^{1}$ Merchant Marine College, Shanghai Maritime University, Shanghai 201306, China \\ ${ }^{2}$ Marine Engineering Department, Nantong Shipping College, Nantong 226010, Jiangsu, China \\ Correspondence should be addressed to Yuanqing Wang; wangyqdmu@163.com
}

Received 23 August 2019; Revised 8 December 2019; Accepted 30 December 2019; Published 22 February 2020

Academic Editor: Jorge Rivera

Copyright (c) 2020 Yuanqing Wang et al. This is an open access article distributed under the Creative Commons Attribution License, which permits unrestricted use, distribution, and reproduction in any medium, provided the original work is properly cited.

In this paper, in order to handle the nonlinear system and the sophisticated disturbance in the marine engine, a finite-time convergence control method is proposed for the diesel engine rotating speed control. First, the mean value model is established for the diesel engine, which can represent response of engine fuel injection to engine speed. Then, in order to deal with parameter perturbation and load disturbance of the marine diesel engine, a finite-time convergence active disturbance rejection control (ADRC) is proposed. At the last, simulation experiments are conducted to verify the effectiveness of the proposed controller under the different load disturbances for the 7RT-Flex60C marine diesel engine. The simulation results demonstrate that the proposed control scheme has better control effect and stronger anti-interference ability than the linear ADRC.

\section{Introduction}

For the energy efficient and environmental friendly, diesel engines are widely used in ship transportation $[1,2]$. For ship propulsion systems, the primary task of the control system of the diesel engine is to keep the speed steady in the inherently unstable and unpredictable external environment [3]. With the development of diesel engine technology, electronically controlled diesel engines have replaced mechanically controlled, and many speed control methods have been developed [4]. These methods fall into two main categories: model-based control method and black box method [5]. The control methods based on the model mainly include adaptive control, system identification, robust control, variable structure control, stochastic system theory, and optimal control [6-8]. These above methods depend on an accurate mathematical model, but it is difficult to achieve in practical engineering applications. Different from the first method, the black box method does not need precise mathematical model and usually includes the classic PID control [9], fuzzy control [10], and active disturbance rejection control (ADRC) [11] as mentioned previously.

The speed control effect of the diesel engine is affected strongly by the inherently unstable and unpredictable external load disturbances; therefore, the active disturbance rejection control has attracted much attention due to its excellent disturbance resistance [12-14]. In the theory of ADRC, both inherently unstable and unpredictable external load disturbances are treated as a "total disturbance," which is expanded to a new state of the system and then estimated and compensated by the extended state observer (ESO) [15-17]. Due to its excellent antidisturbance ability, ADRC has been widely used in industrial applications. Castillo et al., Zheng et al., and Gao proposed a linear active disturbance rejection control (LADRC), which reduced its adjustment parameters to two, greatly promoting its industrial application [18-20]. Compared with the wide application and theoretical research of LADRC, it is noted that the nonlinear ESO proposed in this manuscript is rarely studied $[2,21]$. Therefore, it is essential to further study the nonlinear extended observer. 
According to the theory of the active disturbance rejection control, the ADRC nonlinear state error feedback control law is similar to the PD control and converges to the equilibrium point when time tends to be infinite, and the convergence time is not controllable. Finite-time control has higher accuracies, faster convergence rates, and better disturbance rejection properties. Meanwhile, the convergence time of the finite-time control method is controllable. In recent years, finite-time convergence theory has attracted wide attention $[22,23]$. However, we know that finite-time convergence theory is rarely used in ADRC.

In this paper, a new ADRC method, which can converge in finite time for uncertain nonlinear systems, is designed. According to the theory of ADRC, the possibly unknown diesel system dynamics, external load disturbance and parameter perturbation, are treated as an extended state of the system, which are estimated and compensated in real time by a new ESO. This new type of ESO, which is established by inverse hyperbolic sine function, has fewer adjustment parameters and simple theoretical analysis. On the basis of feedback linearization of the ESO, the sliding mode error feedback control law is designed based on the theory of finite-time convergence [24]. According to Lyapunov stability theory, the control law can converge in finite time.

The content of this article is as follows. In the "Mathematic model" section, the mathematic model of the diesel engine is established. In the "ADRC design" section, inverse hyperbolic sine function is used to design nonlinear ESO, and the new nonlinear ESO method, which has few adjustment parameters, is used to observe and compensate various load disturbances of the diesel engine. And then, we design a finite-time sliding mode controller for ADRC, and it is proved that the controller can converge in finite time. In the "Simulation experiments" section, several experiments are carried out with load disturbance and speed fluctuation, respectively, and the performance of the finite-time active disturbance rejection control (FT-SADRC) is compared with the linear ADRC. In the "Conclusion" section, the last paragraph will summarize the research work of this paper.

\section{Mathematical Model}

In this paper, the research object is the 7RT-Flex60C diesel engine. The maximum sustained power is $16520 \mathrm{~kW}$, and the rated speed is $114 \mathrm{rpm}$. This paragraph established the mean value model of the diesel engine $[25,26]$. The details are as follows:

$$
\begin{aligned}
\frac{\mathrm{d} n_{\mathrm{e}}}{\mathrm{d} t}= & -\frac{10^{3} V_{d}\left(k_{1} n_{\mathrm{e}}+k_{2} n_{\mathrm{e}}^{2}\right)}{N_{\mathrm{st}} I} \frac{30}{\pi^{2}}-\frac{K_{\mathrm{Q}} \rho n_{\mathrm{e}}^{2} D^{5}}{I} \frac{30}{\pi} \\
& +\left(\frac{30}{\pi}\right)^{2} \frac{10^{3} \eta_{i} H_{u} \dot{m}_{f}}{n_{\mathrm{e}} I},
\end{aligned}
$$

where $n_{e}(t)$ is the diesel engine speed, $V_{d}$ is the volume of air cylinder per cycle, $k_{1}, k_{2}$ is the coefficient of fitting function, $N_{\text {st }}$ is the number of strokes, $K_{Q}$ is the torque coefficient, $\rho$ is the seawater density, $D$ is the diameter of the propeller, $\eta_{i}$ is the thermal efficiency, $I$ is the total inertia of the diesel engine, shaft system, and propeller, $H_{u}$ is the low heat value of the fuel, and $\dot{m}_{f}$ is the average mass of fuel flowing into the cylinder per cycle. Suppose $u=\dot{m}_{f}, f\left(n_{\mathrm{e}}(t)\right)=-\left(\left(10^{3} V_{d}\right.\right.$ $\left.\left.\left(k_{1} n_{\mathrm{e}}(t)+k_{2} n_{\mathrm{e}}(t)^{2}\right)\right) / N_{\mathrm{st}} I\right)\left(30 /(\pi)^{2}\right)-\left(\left(K_{\mathrm{Q}} \rho n_{\mathrm{e}}(t)^{2} D^{5}\right) / I\right)$ $(30 / \pi), g\left(n_{\mathrm{e}}(t)\right)=(30 / \pi)^{2}\left(\left(10^{3} \eta_{i} H_{u}\right) /\left(n_{\mathrm{e}}(t) I\right)\right)$, then formula (1) can be expressed as $\left(\mathrm{d} n_{\mathrm{e}} / \mathrm{d} t\right)=f\left(n_{\mathrm{e}}\right)+g\left(n_{\mathrm{e}}\right) u$.

We define $x_{1}(t)=\int n_{\mathrm{e}}(t) \mathrm{d} t$ and $x_{2}(t)=n_{\mathrm{e}}(t)$. Then, the state-space model can be obtained:

$$
\left\{\begin{array}{l}
\dot{x}_{1}(t)=x_{2}(t) \\
\dot{x}_{2}(t)=f\left(x_{1}(t), x_{2}(t)\right)+g\left(x_{1}(t), x_{2}(t)\right) u \\
\quad-b_{0} u(t)+b_{0} u(t), \\
y=x_{2}(t)
\end{array}\right.
$$

where $b_{0}>0$ is the input channel process gain, treated as a (locally) constant parameter; $y$ is the system output; and $u$ is the control input for the system.

The load perturbation of the diesel engine is the disturbance caused by complex sea conditions. The ADRC system with load disturbance characteristics is shown in Figure 1.

According to the working principle of Figure 1, the control system with load disturbance can be expressed as follows:

$$
\left\{\begin{array}{l}
\dot{x}_{1}(t)=x_{2}(t) \\
\dot{x}_{2}(t)=f\left(x_{1}(t), x_{2}(t)\right)+g\left(x_{1}(t), x_{2}(t)\right) u(t) \\
\quad-b_{0} u(t)+b_{0} u(t)+l(t), \\
y=x_{2}(t)
\end{array}\right.
$$

where $l(t)$ is the system load disturbance, $|l(t)<L|$, and $L$ is a constant. Here,

$$
f\left(x_{1}(t), x_{2}(t)\right)+g\left(x_{1}(t), x_{2}(t)\right) u(t)-b_{0} u(t)+l(t)
$$

is the new lumped disturbance and has bounded. We define that

$$
x_{3}(t)=f\left(x_{1}(t), x_{2}(t)\right)+g\left(x_{1}(t), x_{2}(t)\right) u(t)-b_{0} u(t)+l(t)
$$

as the extended state, and suppose $\dot{x}_{3}=o(t)$. Equation (3) is extended in the following equation:

$$
\left\{\begin{array}{l}
\dot{x}_{1}(t)=x_{2}(t) \\
\dot{x}_{2}(t)=x_{3}(t)+b_{0} u(t) \\
\dot{x}_{3}(t)=o(t) \\
y(t)=x_{2}(t)
\end{array}\right.
$$

\section{Controller Design}

The ADRC approach consists of three modules: tracking differentiator (TD), extended state observer (ESO), and nonlinear state error feedback control law (NLSEF) [27]. TD 


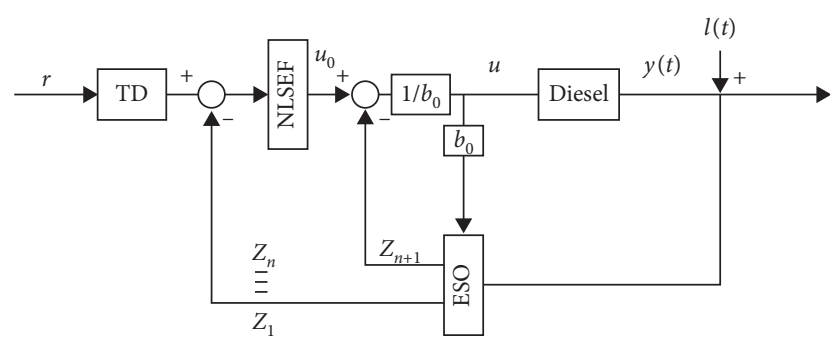

FIgURE 1: The propulsion control system with load disturbances.

generates a transient trajectory to avoid the setpoint jump. The system's total disturbance is estimated by the ESO. The NLSEF is a nonlinear PD controller.

The modules' design is independent. Each module can be designed separately according to the controlled object and combined together to acquire the ADRC controller. For system equation (6), the TD in the continuous form is as follows:

$$
\left\{\begin{array}{l}
\dot{v}_{1}(t)=v_{2}(t), \\
\dot{v}_{2}(t)=R^{2}\left\{-a_{1}\left|e_{1}\right| \operatorname{arsh}\left(e_{1}\right)-a_{2}\left|e_{2}\right| \operatorname{arsh}\left(e_{2} / R\right)\right\},
\end{array}\right.
$$

where arsh is the inverse hyperbolic sine function [28] $\left(\operatorname{arsh}(x)=\ln \left(x+\sqrt{x^{2}+1}\right)\right) ; \quad e_{1}(t)=\int e_{2}(t) \mathrm{d} t, \quad e_{2}(t)=$ $v_{2}(t)-r(t) ; r(t)$ is the system reference signal; $\mathbf{R}>0, a_{1}>0$, $a_{2}>0$. For any bounded integrable function $r(t)$, the tracking value of $r(t)$ is $v_{2}(t)$ which satisfies the following formula:

$$
\lim _{R \rightarrow \infty} \int_{0}^{T}\left|v_{2}(t)-r(t)\right| \mathrm{d} t=0
$$

where $T>0$.

The ESO is selected as follows:

$$
\left\{\begin{array}{l}
e_{3}(t)=z_{1}(t)-\int_{0}^{t} y(t) \mathrm{d} t, \\
\dot{z}_{1}(t)=z_{2}(t)-\beta_{1} e_{3}(t), \\
\dot{z}_{2}(t)=z_{3}(t)-\beta_{2} \cdot \operatorname{arsh}\left(e_{3}(t)\right)+b_{0} u(t), \\
\dot{z}_{3}(t)=-\beta_{3} \cdot \operatorname{arsh}\left(e_{3}(t)\right),
\end{array}\right.
$$

where $\beta_{1}>0, \beta_{2}>0$, and $\beta_{3}>0 . z_{1}(t)$ and $z_{2}(t)$ track the output variable $x_{1}(t)$ and $x_{2}(t)$, respectively. $x_{3}(t)$ is the extended state and is used to estimate the total disturbance. For the ESO, the method of parameter tuning is used and described as follows [29]:

$$
\begin{aligned}
& \beta_{1}=9 v_{\text {eso }}, \\
& \beta_{2}=27 v_{\text {eso }}^{2}, \\
& \beta_{3}=27 v_{\text {eso }}^{3},
\end{aligned}
$$

where $v_{\text {eso }}$ is the observer observation speed. Because of $\beta_{1} \beta_{2}-\beta_{3}=243 v_{\text {eso }}^{3}-27 v_{\text {eso }}^{3}$ and $\omega_{\text {eso }}>0$, the stability condition of the observer can be satisfied [30]: $\beta_{1} \beta_{2}-\beta_{3}>0$.

In order to improve the control performance, we apply the sliding mode error feedback control law to the ADRC. We definee $e_{6}(t)=\int e_{7}(t) \mathrm{d} t$ and $e_{7}(t)=y(t)-r=x_{2}(t)-r$.
Here, $r$ is the system reference signal. And hence, the error system corresponding to equation (6) is

$$
\left\{\begin{array}{l}
\dot{e}_{6}(t)=e_{7}(t) \\
\dot{e}_{7}(t)=f\left(x_{1}(t), x_{2}(t)\right)+g\left(x_{1}(t), x_{2}(t)\right) u(t) \\
\quad-b_{0} u(t)+b_{0} u(t)+l(t) .
\end{array}\right.
$$

In order to apply the ADRC, a following governing action is proposed: $u(t)=\left(u_{0}(t)-z_{3}(t)\right) / b_{0}$ [31], and system (11) can be rewritten as

$$
\left\{\begin{aligned}
& \dot{e}_{6}(t)=e_{7}(t) \\
& \dot{e}_{7}(t)=f\left(x_{1}(t), x_{2}(t)\right)+g\left(x_{1}(t), x_{2}(t)\right) u(t) \\
& \quad-b_{0} u(t)+l(t)+u_{0}(t)-z_{3}(t)
\end{aligned}\right.
$$

where $u_{0}(t)$ is the new control input for the system, which can be designed even as formula (21).

Due to the expansion of observer (9) convergence, that is, $z_{1}(t) \longrightarrow x_{1}(t), \quad z_{2}(t) \longrightarrow x_{2}(t), \quad z_{3}(t) \longrightarrow x_{3}(t)=$ $f\left(x_{1}(t), x_{2}(t)\right)+g\left(x_{1}(t), x_{2}(t)\right) u(t)-b_{0} u(t)+l(t)$. System (12) can be rewritten as

$$
\left\{\begin{array}{l}
\dot{e}_{6}(t)=e_{7}(t) \\
\dot{e}_{7}(t)=u_{0}(t)
\end{array}\right.
$$

And then, we introduce the theory of finite-time convergence.

For the nonlinear systems [32],

$$
\dot{x}=g(x), \quad x \subseteq R^{n}, g(0)=0,
$$

where $f: D \longrightarrow R^{n}$ satisfies the locally Lipschitz continuous condition. $x=\left[x_{1}, x_{2}, \ldots, x_{n}\right]^{T}$ is the state.

Lemma 1 (see [31]). For system (14), if there exist any real numbers and $0<\beta<1, \beta \in C^{1}$, radially unbounded Lyapunov function $V(x)$, the system such that $V(x) \leq-k V^{\beta}(x), k>0$, then system (14) is global finite-time stable. The settling time $x_{0}$ satisfies $T_{x}\left(x_{0}\right) \leq\left(V^{1-\alpha}\left(x_{0}\right)\right) / c(1-\alpha)$.

In the following, finite-time stability theory is used to analyze the convergence of the sliding mode error feedback control.

And then, we design a finite-time convergence error feedback control rate for ADRC.

Definition 1. For system (6), we design the system control input as equation (17).

$$
u(t)=\frac{1}{b_{0}}\left(-z_{3}(t)-k_{1} \gamma\left|e_{6}(t)\right|^{\gamma-1} e_{7}(t)-\frac{\alpha}{\mathbf{R}} \operatorname{sgn}(s)|s|^{\eta}\right),
$$

where $0<\gamma<1, k_{1}>0, \alpha>0$, and $\eta>0$. Then, the state error $e_{6}(t)$ and $e_{7}(t)$ converges to zero in finite time, and the diesel engine speed $x_{2}(t)$ converges to $r$. Convergence time will be satisfied in equation (23).

$$
T_{H} \leq \frac{R_{0} s^{(1-\eta)}(0)}{\alpha(1-\eta)}+\frac{S^{(1-\gamma)}(0)}{k_{1}(1-\gamma)} .
$$


Proof. According to sliding mode control theory, we choose the sliding surface as follows [33]:

$$
S=e_{7}(t)+k_{1}\left|e_{6}(t)\right|^{\gamma} \operatorname{sgn}\left(e_{6}(t)\right),
$$

where $0<\gamma<1$ and $k_{1}>0$.

Because the sliding surface satisfies $S \dot{S} \leq 0$, we define the reaching law as the following equation:

$$
\dot{S}=-\frac{\alpha \operatorname{sgn}(S)}{R}|S|^{\eta}, \quad \alpha>0, \eta>0,
$$

where $R=\left|e_{7}\right|, 0<R<R_{0}$, and $R_{0}=r$.

From (17) and (18), we have

$$
S \dot{S}=-\frac{\alpha}{R}|S|^{\eta+1}<0 .
$$

From equation (19), system (13) can come to the sliding mode surface.

We take the derivative of formula (17), and then connect formulas (13) and (18):

$$
\begin{aligned}
u(t)= & \frac{1}{b_{0}}\left(-f\left(x_{1}(t), x_{2}(t)\right)-g\left(x_{1}(t), x_{2}(t)\right) u(t)\right. \\
& \left.+b_{0} u(t)-l(t)-k_{1} \gamma\left|e_{6}(t)\right|^{\gamma-1} e_{7}(t)-\frac{\alpha}{R} \operatorname{sgn}(s)|s|^{\eta}\right) \\
= & \frac{1}{b_{0}}\left(-z_{3}(t)-k_{1} \gamma\left|e_{6}(t)\right|^{\gamma-1} e_{7}(t)-\frac{\alpha}{R} \operatorname{sgn}(s)|s|^{\eta}\right) .
\end{aligned}
$$

We selected the nonlinear control law as

$$
u_{0}=-k_{1} \gamma\left|e_{6}(t)\right|^{\gamma-1} e_{7}(t)-\frac{\alpha}{R} \operatorname{sgn}(s)|s|^{\eta} .
$$

Therefore, control input can be obtained as

$$
u(t)=\frac{1}{b_{0}}\left(-z_{3}(t)+u_{0}(t)\right) .
$$

And then, we prove that the system converges in finite time. According to sliding mode control theory, the system moves in two steps: (i) the approaching stage; (ii) the sliding state.

The Lyapunov function of the approaching stage can be defined as

$$
V=S^{2} .
$$

If the derivative of equation (23) is taken, we can get

$$
\dot{V}=2 S \dot{S} \text {. }
$$

From equations (13) and (24), we have

$$
\dot{V}=-2 \frac{\alpha}{R}|S|^{\eta+1}<0 .
$$

From formulas (23) and (25), we have

$$
\dot{V}=-2 \frac{\alpha}{R} V^{(1 / 2)(\eta+1)} \text {. }
$$

Consider the operation of the control system $R=\left|e_{7}(t)\right|$, $0<R<R_{0}, R_{0}=r$.

Therefore,

$$
\dot{V} \leq-2 \frac{\alpha}{R_{0}} V^{(1 / 2)(\eta+1)}, \quad \forall t>0 .
$$

According to Lemma 1, the first stage can converge for a finite time. Convergence time $T_{1}$ satisfaction is

$$
T_{1} \leq \frac{R_{0} V^{(1 / 2)(1-\eta)}(0)}{\alpha(1-\eta)}=\frac{R_{0} S^{1-\eta}(0)}{\alpha(1-\eta)} .
$$

And then, the system will move along the surface until it converges to zero. So, the state meets the following requirements:

$$
S=e_{7}(t)+k_{1}\left|e_{6}(t)\right|^{\gamma} \operatorname{sgn}\left(e_{6}(t)\right)=0 .
$$

Consider that

$$
\dot{e}_{6}(t)=e_{7}(t) .
$$

And hence, from formulas (29) and (30), we have

$$
\dot{e}_{6}(t)=k_{1}\left|e_{6}(t)\right|^{\gamma} \operatorname{sgn}\left(e_{6}(t)\right) \text {. }
$$

We define that

$$
e_{6}=S^{\prime} .
$$

Formula (31) can be written as

$$
\dot{S}^{\prime}=k_{1}\left|S^{\prime}\right|^{\gamma} \operatorname{sgn}\left(S^{\prime}\right) .
$$

Choose the Lyapunov function for formula (33) as follows:

$$
V^{\prime}=S^{\prime 2} .
$$

And then, we have the time derivative of $V^{\prime}$

$$
\dot{V}^{\prime}=2 S^{\prime} \dot{S}^{\prime} .
$$

From formulas (31) and (33), we have

$$
\dot{V}^{\prime}=-2 k_{1}\left|S^{\prime}\right|^{(\gamma+1)} \leq 0 .
$$

According to Lemma 1, the convergence time of system (33) satisfies

$$
T_{2} \leq \frac{V^{(1 / 2)(1-\gamma)(0)}}{k_{1}(1-\gamma)}=\frac{S^{(1-\gamma)}(0)}{k_{1}(1-\gamma)} .
$$

Therefore, the whole convergence time of the control system can be given as

$$
T_{H} \leq T_{1}+T_{2} \leq \frac{R_{0} s^{(1-\eta)}(0)}{\alpha(1-\eta)}+\frac{S^{(1-\gamma)}(0)}{k_{1}(1-\gamma)} .
$$

The proof of Definition 1 is complete.

Remark 1. In this paper, we use $\operatorname{arsh}(S)$ instead of the sign function $\operatorname{sgn}(S)$. Because it is a smooth function, the 
control process is stable, and the control precision is improved.

\section{Simulation Study}

The research object of this paper is the RT-Flex60C lowspeed marine diesel engine, whose main parameters are shown in Table 1.

In order to verify the control effect of the proposed algorithm, the simulation experiment of the proposed method (FT-SADRC) is compared with the linear ADRC in different circumstances.

4.1. Analysis of the Diesel Engine Running in the Bad Sea Condition. When ships encounter such bad sea conditions as typhoons and tangled propellers, the simulation analysis of the ship propulsion control system under load torque variation is carried out. Here, as an unknown external disturbance, $l(t)$ is $25 \times 10^{3} \sin (t \cdot 20 \pi) \mathrm{N} \cdot \mathrm{m}$, the simulation time is set to $100 \mathrm{~s}$, and the initial speed of the diesel engine is rated speed $114 \mathrm{r} / \mathrm{min}$. In the process, the load torque of the propeller is $1390 \mathrm{kN} \cdot \mathrm{m}$. At $50 \mathrm{~s}$, the load torque was suddenly reduced to $900 \mathrm{kN} \cdot \mathrm{m}$ to simulate the propeller load change for the wind and waves.

Ge et al. proposed a tuning method based on observer bandwidth for LADRC [29]. In this test, the bandwidth of the observer $\omega_{0}=37$ and the bandwidth of the controller $\omega_{c}=3.5$.

FT-SADRC parameter is selected as follows: $R=10$, $b_{0}=1000 v_{\text {eso }}=2, k_{1}=0.6, \gamma=0.8$, and $\alpha=0.4$.

The comparison of simulation experiments under load disturbance is shown in Figures $2-8$. We can find the following:

(1) It can be seen from Figures 2-4 that the new ESO can better track the system state quantity, and because it has few adjusting parameters and simple theoretical analysis, it is conducive to practical engineering application.

(2) Although two kinds of control methods can achieve good control effect, the rotation speed error of the FT-SADRC is obviously smaller than that of LADRC, and the speed error of the FT-SADRC and the LADRC are 0.559 and $1.785 \mathrm{r} / \mathrm{min}$, respectively.

(3) In Figures 7 and 8, we find that control input and torque are smaller for the FT-SADRC, which can save energy and reduce actuator wear.

4.2. Analysis of Maneuvering Operation. In this section, the simulation analysis is carried out on the working conditions of ship maneuvering such as entering and leaving port, overtaking and avoiding, without considering the influence of wind waves, ship inertia, and other factors. Here, as an unknown external disturbance, $l(t)$ is $25 \times 10^{3}$ $\sin (t \cdot 20 \pi) \mathrm{N} \cdot \mathrm{m}$, the simulation time is set to $100 \mathrm{~s}$, and the initial speed of the diesel engine is rated speed $114 \mathrm{r} / \mathrm{min}$. In the process, the load torque of the propeller is $1390 \mathrm{kN} \cdot \mathrm{m}$, and then, the given rotation speed of the bridge is set to
TABLE 1: RT-Flex60C engine parameters.

\begin{tabular}{lc}
\hline Parameters & Value \\
\hline Amount of cylinders & 7 \\
Stroke & $2250 \mathrm{~mm}$ \\
Crank link ratio & 0.489 \\
Compression ratio & 18.4 \\
Stroke number & 2 \\
Cylinder diameter & $600 \mathrm{~mm}$ \\
Rated speed & $114 \mathrm{r} / \mathrm{min}$ \\
Rated power & $16520 \mathrm{~kW}$ \\
Rated torque & $1390 \mathrm{kN} \cdot \mathrm{m}$ \\
Specific fuel consumption & $177 \mathrm{~g} / \mathrm{kWh}$ \\
\hline
\end{tabular}

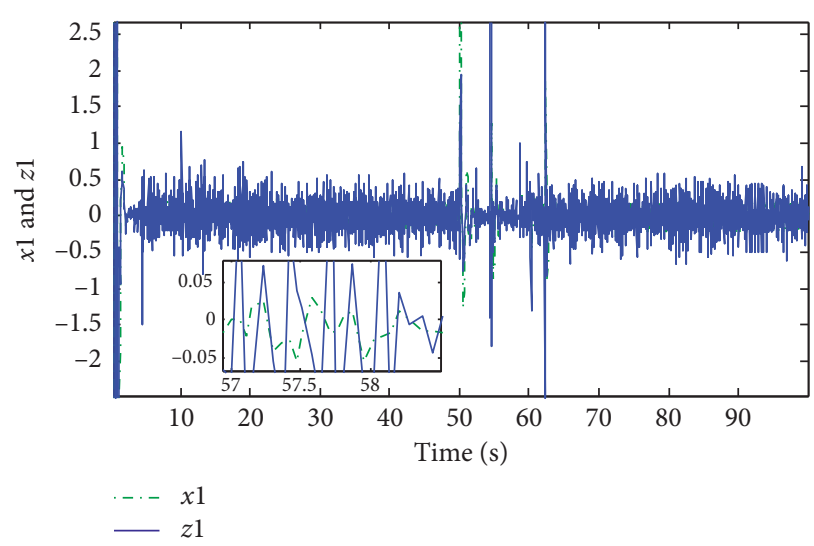

FIgURE 2: $x 1$ and $z 1$ curve.

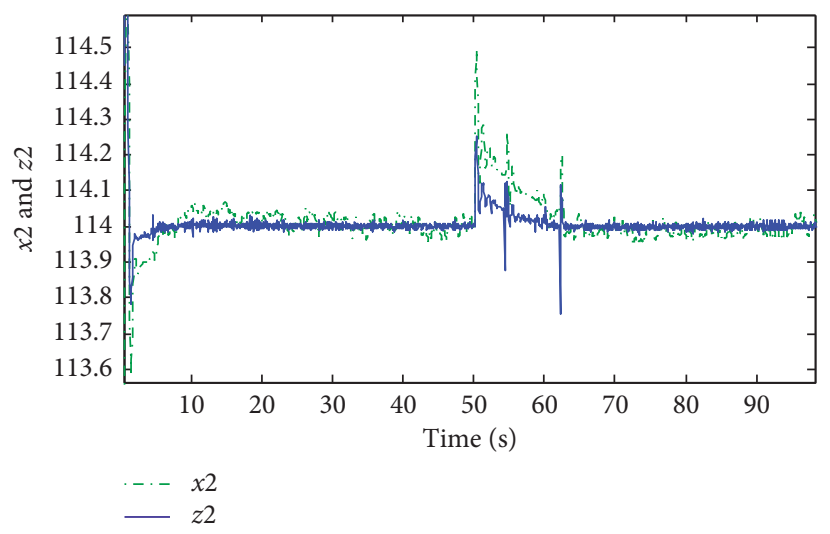

Figure $3: x 2$ and $z 2$ curve.

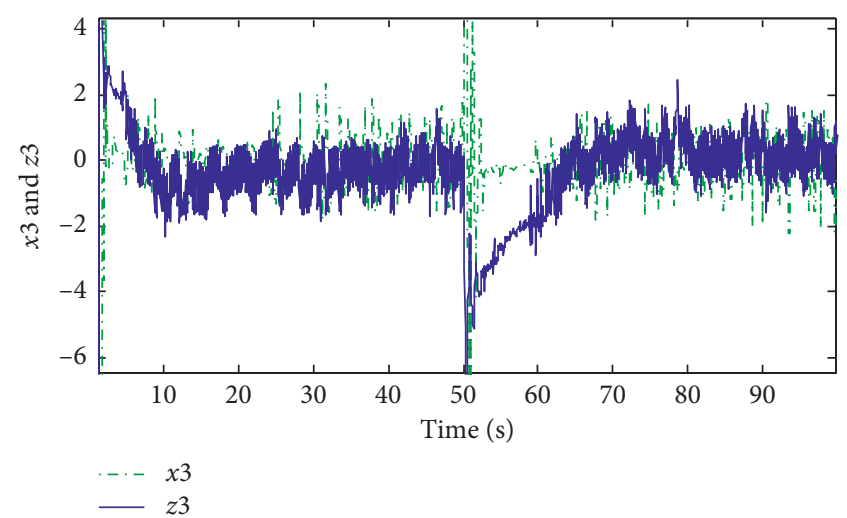

Figure $4: x 3$ and $z 3$ curve. 


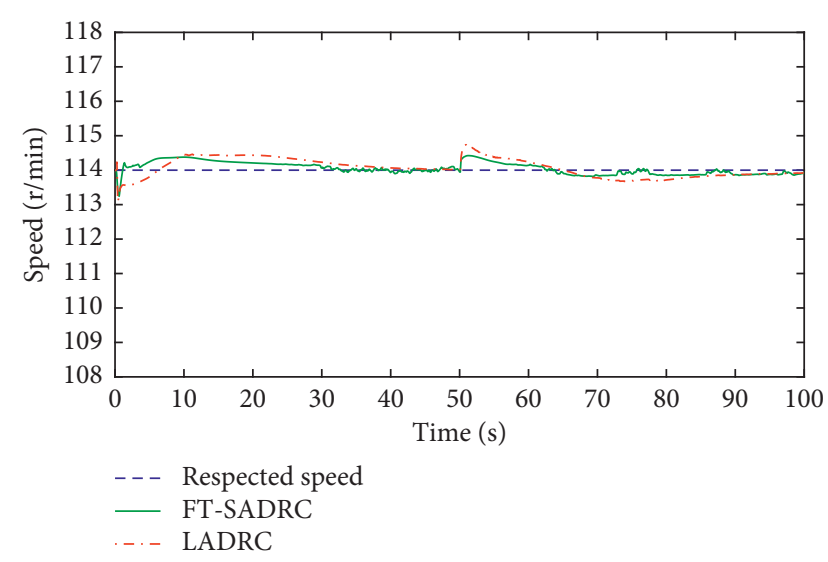

FIgURE 5: Diesel engine speed y curve.

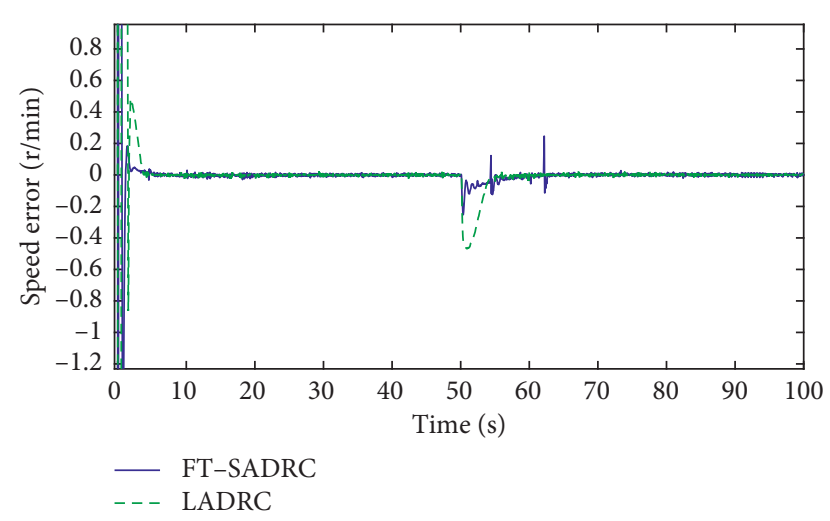

Figure 6: Speed error curve.

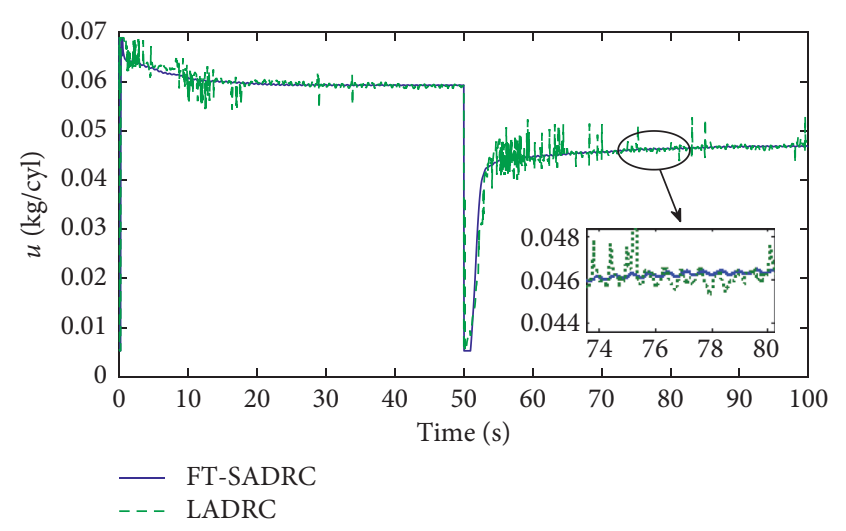

FIgure 7: Diesel engine control input u curve.

$90.5 \mathrm{r} / \mathrm{min}$ in $30 \mathrm{~s}$ and to $103.6 \mathrm{r} / \mathrm{min}$ in $60 \mathrm{~s}$ according to the maneuvering navigation conditions.

For LADRC [29], the bandwidth of the observer $\omega_{0}=43$, and the bandwidth of the control $\omega_{c}=4.1$. FT-SADRC parameter is selected as follows: $R=10, b_{0}=1000, v_{\text {eso }}=2.7$, $k_{1}=0.4, \gamma=0.9$, and $\alpha=0.5$.

From Figure 9, the maximum speed of the proposed FTSADRC method is less than that of the LADRC method, and

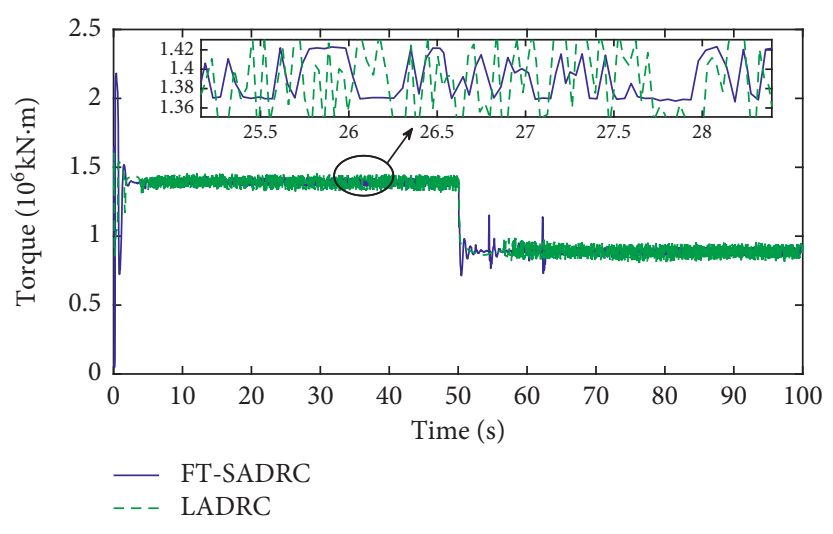

Figure 8: Diesel engine torque curve.

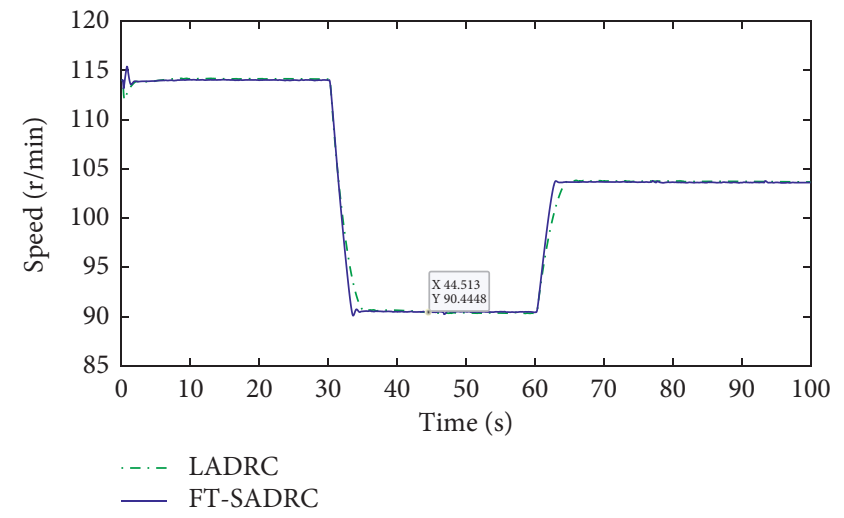

FIgURe 9: Diesel engine speed curve.

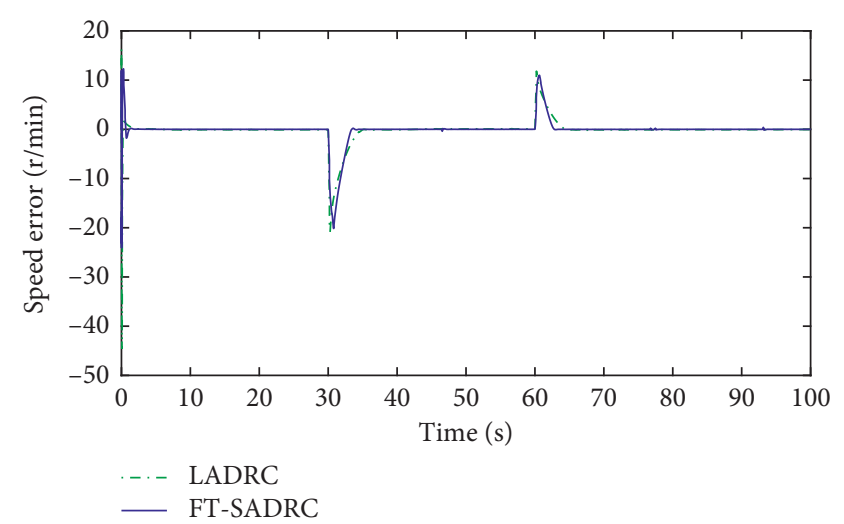

Figure 10: Speed error curve.

the time required to restore normal speed is also less than that of the LADRC method.

From Figure 10, it can be seen that the control input of FT-SADRC requires only about $3 \mathrm{~s}$ from sudden dumping load to restore stability while the LADRC requires more than $5 \mathrm{~s}$. Therefore, the adjustment speed of the control input of the proposed method is faster than that of LADRC.

Besides, from Figures 11 and 12, when ship maneuvering, the FT-SADRC method has small fluctuation, which 


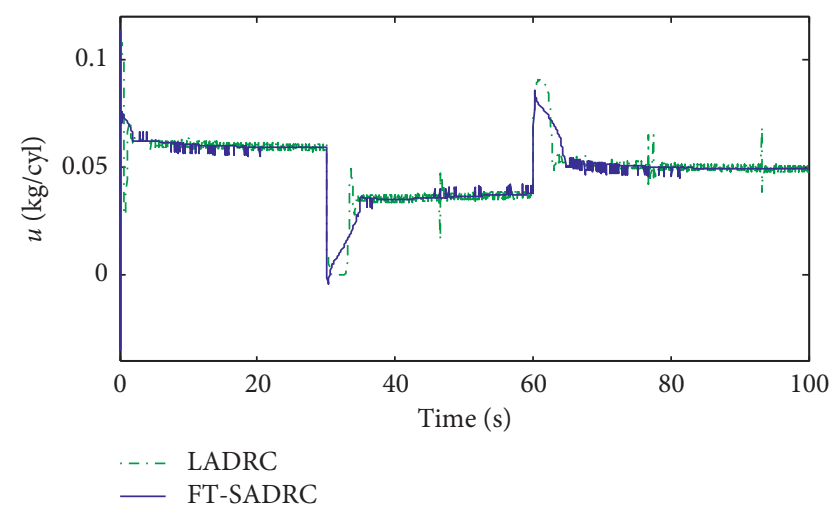

FIGURE 11: Diesel engine control input curve.

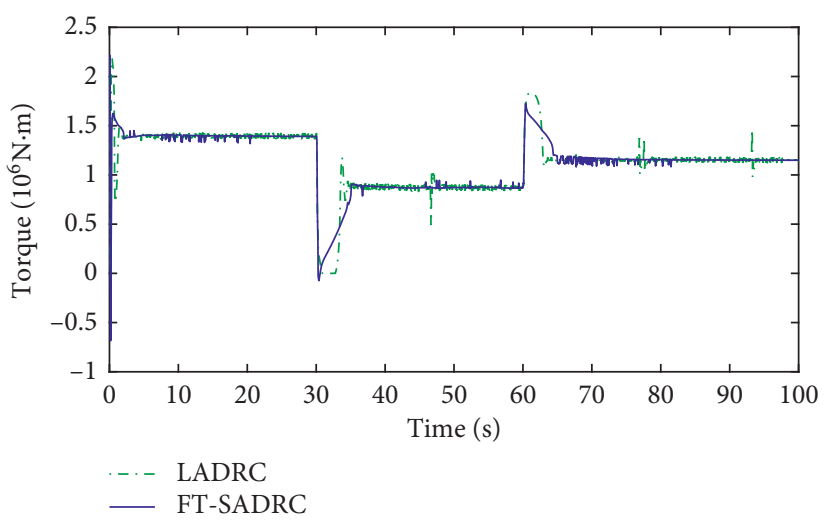

FIgURE 12: Diesel engine torque curve.

is beneficial to reduce the vibration of the equipment and extend the service life of the equipment.

\section{Conclusions}

In view of the marine diesel engine speed control problem under the random load disturbances and unknown uncertainties, the sliding-mode control method is put forward by combining a new ESO (based on the inverse hyperbolic sine function). Although the new observer is nonlinear, the adjustment parameters are the same as linear ESO, which reduce the difficulty of application of the nonlinear observer. The control law is constructed by the sliding-mode control for ADRC, and the method can realize finite-time convergence and improve the convergence speed and control precision. From the simulation experiment using the model of a large low-speed two-stroke marine diesel engine RTFlex60c, the proposed method has more advantages than the LADRC method, such as control accuracy and disturbance rejection (both random disturbance and sudden dumping load disturbance).

Then, the main contributions of this article are summarized as follows: (1) in theory, a new ESO and finite-time convergence control law is proposed, which makes full use of the known nonlinear term in the diesel engine model and further improves the adaptability of the controller. The proposed method can be applied to control issues of other systems which have known nonlinear terms. (2) In practical, the proposed method can maintain quick regulation and fewer tuning parameters of diesel engine speed under different external and system disturbances and has more practical significance compared with LADRC. Actually, the fuel injection signal of a marine diesel engine is usually maintained at several fixed positions for safety and economy. Therefore, the proposed method under a certain output constraint could be considered further.

\section{Data Availability}

These data are based on the mathematical model of the paper and RT-FLEX60c real ship data modeling and simulation. There are simulation models and running results in the attachment.

\section{Conflicts of Interest}

The authors declare that they have no conflicts of interest.

\section{Acknowledgments}

This research was financially supported by the National Natural Science Foundation of China under Grant 51779136 and the Natural Science Foundation of the Higher Education Institutions of Jiangsu Province, China (18KJB413008).

\section{References}

[1] G. Gabiña, L. Martin, O. C. Basurko, M. Clemente, S. Aldekoa, and Z. Uriondo, "Performance of marine diesel engine in propulsion mode with a waste oil-based alternative fuel," Fuel, vol. 235, pp. 259-268, 2019.

[2] S. Xie, X. Chu, C. Liu, and M. Zheng, "Marine diesel engine speed control based on adaptive state-compensate extended state observer-backstepping method," Proceedings of the Institution of Mechanical Engineers, Part I: Journal of Systems and Control Engineering, vol. 233, no. 5, pp. 457-471, 2019.

[3] J. Tang, Y. Lei, G. Nie et al., "Application of PID neural network in control of diesel engine speed," Coal Mine Machinery, vol. 1, pp. 201-204, 2010.

[4] T. I. Bø, T. A. Johansen, A. J. Sørensen, and E. Mathiesen, "Dynamic consequence analysis of marine electric power plant in dynamic positioning," Applied Ocean Research, vol. 57, pp. 30-39, 2016.

[5] X. Yan, L. Xu, and Y. Wang, "The loading control strategy of the mobile dynamometer vehicle based on neural network PID," Mathematical Problems in Engineering, vol. 2017, Article ID 5658983, 7 pages, 2017.

[6] A. E. Bryson, Applied Optimal Control: Optimization, Estimation and Control, Routledge, Abingdon, UK, 2018.

[7] Y.-J. Liu, S. Lu, S. Tong, X. Chen, C. L. P. Chen, and D.-J. Li, "Adaptive control-based barrier Lyapunov functions for a class of stochastic nonlinear systems with full state constraints," Automatica, vol. 87, pp. 83-93, 2018.

[8] V. Utkin, J. Guldner, and J. Shi, Sliding Mode Control in Electro-Mechanical Systems, CRC Press, Boca Raton, FL, USA, 2017.

[9] W. Cui, R. Guo, and D. Fan, "Application of neural network PID control in hump pushing peak process," DEStech 
Transactions on Computer Science and Engineering, pp. 230234, 2017.

[10] A. A. El-Samahy and M. A. Shamseldin, "Brushless DC motor tracking control using self-tuning fuzzy PID control and model reference adaptive control," Ain Shams Engineering Journal, vol. 9, no. 3, pp. 341-352, 2018.

[11] R. Wang, X. Li, Y. Liu et al., "Variable sampling rate based active disturbance control for a marine diesel engine," Electronics, vol. 8, no. 4, p. 370, 2019.

[12] W. Yao, Research on Model-Free Adaptive Vector Control Strategy of Ship Podded Propulsion Motor, Dalian Maritime University, Dalian, China, 2015.

[13] J. Lin, Y. Zhang, Y. Yang, Y. Sun, and T. Lin, "Anti-saturation system for surface nuclear magnetic resonance in efficient groundwater detection," Review of Scientific Instruments, vol. 88, no. 6, Article ID 064702, 2017.

[14] G. Li and M. Xin, "A three-dimensional anti-saturation terminal guidance law with finite-time convergence," in Proceedings of the American Control Conference (ACC), pp. 2243-2248, Seattle, WC, USA, May 2017.

[15] F. Wang, Y. Guo, K. Wang, Z. Zhang, C. Hua, and Q. Zong, "Disturbance observer based robust backstepping control design of flexible air-breathing hypersonic vehicle," IET Control Theory \& Applications, vol. 13, no. 4, pp. 572-583, 2019.

[16] Z. Wu, T. He, D. Li, Y. Xue, L. Sun, and L. Sun, "Superheated steam temperature control based on modified active disturbance rejection control," Control Engineering Practice, vol. 83, pp. 83-97, 2019.

[17] A. Tavasoli, "Active disturbance rejection boundary control of Timoshenko beam with tip mass," ISA Transactions, vol. 80, pp. 221-231, 2018.

[18] A. Castillo, P. García, R. Sanz, and P. Albertos, "Enhanced extended state observer-based control for systems with mismatched uncertainties and disturbances," ISA Transactions, vol. 73, pp. 1-10, 2018.

[19] Q. Zheng, Z. Ping, S. Soares et al., "An active disturbance rejection control approach to fan control in servers," in Proceedings of the IEEE Conference on Control Technology and Applications (CCTA), pp. 294-299, IEEE, Copenhagen, Denmark, August 2018.

[20] Z. Gao, "Scaling and bandwidth-parameterization based controller tuning," in Proceedings of the American Control Conference, pp. 4989-4996, IEEE, Denver, CO, USA, June 2003.

[21] R. Wang, X. Li, J. Zhang et al., "Speed control for a marine diesel engine based on the combined linear-nonlinear active disturbance rejection control," Mathematical Problems in Engineering, vol. 2018, Article ID 7641862, 18 pages, 2018.

[22] T. Li, J. Yang, C. Wen, and C. Zhang, "Global adaptive finitetime stabilization of uncertain time-varying $p$-normal nonlinear systems without homogeneous growth nonlinearity restriction," IEEE Transactions on Automatic Control, vol. 64, no. 11, pp. 4637-4644, 2019.

[23] X. Zhang, X. Li, J. Cao, and F. Miaadi, "Design of memory controllers for finite-time stabilization of delayed neural networks with uncertainty," Journal of the Franklin Institute, vol. 355, no. 13, pp. 5394-5413, 2018.

[24] K.-N. Wu, H.-X. Sun, P. Shi, and C.-C. Lim, "Finite-time boundary stabilization of reaction-diffusion systems," International Journal of Robust and Nonlinear Control, vol. 28, no. 5, pp. 1641-1652, 2018.

[25] G. Theotokatos, C. Guan, H. Chen, and I. Lazakis, "Development of an extended mean value engine model for predicting the marine two-stroke engine operation at varying settings," Energy, vol. 143, pp. 533-545, 2018.

[26] Y. Wang, Q. Wang, J. Yuan et al., "Study and application of finite time convergence ADRC with dead zone and antisaturation disturbance compensation," IOP Conference Series: materials Science and Engineering, vol. 677, no. 4, Article ID 042002, 2019.

[27] Z. Huang, Y. Liu, H. Zheng, S. Wang, J. Ma, and Y. Liu, "A self-searching optimal ADRC for the pitch angle control of an underwater thermal glider in the vertical plane motion," Ocean Engineering, vol. 159, pp. 98-111, 2018.

[28] M. F. Bellemare and C. J. Wichman, "Elasticities and the inverse hyperbolic sine transformation," University of Minnesota, Minneapolis, MN, USA, 2018.

[29] L. M. Ge, Z. G. Li, S. W. Wang et al., "Parameter-tuning of active disturbance rejection control based on settling/observing time," Control and Decision, vol. 32, no. 7, pp. 1333-1337, 2017.

[30] L. Chen, G. Chen, R. Wu, J. A. Tenreiro Machado, A. M. Lopes, and S. Ge, "Stabilization of uncertain multi-order fractional systems based on the extended state observer," Asian Journal of Control, vol. 20, no. 3, pp. 1263-1273, 2018.

[31] H. Sira-Ramírez, E. W. Zurita-Bustamante, and C. Huang, "Equivalence among flat filters, dirty derivative-based PID controllers, ADRC, and integral reconstructor-based sliding mode control," IEEE Transactions on Control Systems Technology, 2019.

[32] S. Bhat and D. Bernsein, "Lyapunov analysis of finite-time differential equations," in Proceedings of the American Control Conference, pp. 1831-1832, Seattle, WC, USA, June 1995.

[33] R. Galván-Guerra, L. Fridman, R. Iriarte, J.-E. VelázquezVelázquez, and M. Steinberger, "Integral sliding-mode observation and control for switched uncertain linear time invariant systems: a robustifying strategy," Asian Journal of Control, vol. 20, no. 4, pp. 1551-1565, 2018. 